\section{A Specific Diffusible Antigen of Rinderpest Virus demonstrated by the Agar Double-Diffusion Precipitation Reaction}

Is recent years diffusible antigens of many viruses have been demonstrated by the double-diffusion precipitation reaction in agar. Early attempts in this laboratory to demonstrate such antigens associated with rinderpest virus failed, probably because the convalescent bovine and rabbit sera used did not contain a sufficiently high concentration of antibody.

An antigen was demonstrated, however, employing Mansi's modification ${ }^{1}$ of Ouchterlony's technique ${ }^{2}$ and hyper-immune serum prepared in rabbits. Rabbits were hyper-immunized by inoculation of the relatively avirulent, lapinized-avianized strain of rinderpest virus $^{3}$, followed seven days later by a series of four intravenous injections of the Nakamura III strain of lapinized virus, which is highly virulent for rabbits. The inoculum consisted of $1 \mathrm{ml}$. of a 25 per cent saline suspension of infected rabbit mesenteric lymph nodes; the interval between injections was two days and serum was collected seven days after the last inoculation.

Lymph nodes, preferably mesenteric, were collected. from cattle killed at various stages after infection with the Kabete $O$ strain of virulent rinderpest virus. These were homogenized, centrifuged and the supernatant fluid was used undiluted. No reaction was produced by lymph nodes of uninfected cattle but a strong single line of precipitation was produced within $24 \mathrm{hr}$. by nodes of infected animals harvested on the second day of the temperature reaction. The heaviest lines were produced by mesenteric nodes of cattle killed on the fifth day of pyrexia, the reaction thereafter diminishing, to disappear on the eighth day, presumably because of neutralization of the antigen by developing antibody.

Antigen preparations made as described above always produced an opaque haze 1-2 $\mathrm{mm}$. wide around their depots, but the specific precipitate appeared in the remaining clear area between the serum depot and the edge of the hazy region. This haze was entirely eliminated if sodium chloride, usually used at 0.85 per cent concentration, was omitted from the diffusion medium, whereas the precipitation reaction was unaffected.

The stability of the antigen involved in this reaction has not been investigated in detail, but it is quickly destroyed in putrefying tissues, while addition

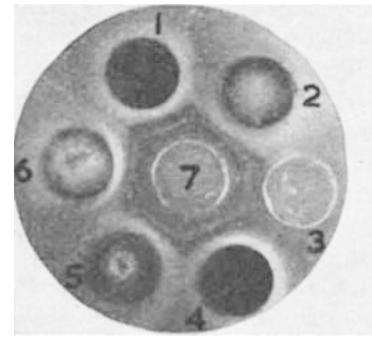

$\boldsymbol{A}$

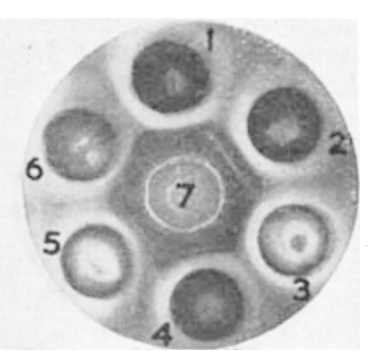

$\boldsymbol{B}$
Fig. 1. $A$ : 1, Infected bovine lymph node ; 2 ; infected goat lymph node; 3 , concentrated infected tissue culture fluid ; 4 , infected bovine lymph node ; 5 , infected rabbit lymph node $; 6$, inmalbovine lymph node; 2 , infected bovine lymph node ; 3 , normal rabbit lymph node ; 4, infected rabbit lymph node ; 5 , infected goat lymph node; 6 , normal goat lymph node ; 7 , hyper-immune of 0.4 per cent of formaldehyde or 0.5 per cent of phenol destroys it in a few hours. However, antigen preparations have been preserved for up to ten days at room tempersture, without loss of activity, by addition of $1 / 10,000$ thiomersalate. $1 / 10,000$ thiomersalate is also incorporated in the diffusion medium. The antigen withstands drying at room temperature, as in the process described by Nakamura and Ishii for the preparation of a complement-fixing antigen.

An antigen identical to that found in the lymph nodes of reacting cattle was detected in the mesenteric nodes of goats four days after infection with Kenya goat-attenuated rinderpest virus, in the rabbit lymph node inoculum used for hyper-immunizing rabbits and in infected tissue culture fluids ${ }^{5}$ concentrated by the method of Svedmyr et al. ${ }^{6}$. Identity of the antigens in all cases was proved by the coalescence of the lines of precipitate formed.

This method of detecting rinderpest antigen in tissues may be of value in the diagnosis of suspected rinderpest outbreaks, especially in regions already free from the disease, as it is a rapid, simple technique and involves no inoculation of animals. It may also be of value in the differential diagnosis of rinderpest from diseases such as the mucosal disease complex of cattle, which may be confused with rinderpest on clinical and post-mortem examination.

\section{East African Veterinary Research Organization, \\ Muguga, Kenya Colony. March 8.}

${ }^{1}$ Mansi, W., J. Comp. Path., 67, 297 (1957).

2 Ouchterlony, O., Ark. Kemi. Mineral. Geol., B, 26, 1 (1948).

s Nakamura, J., and Miyamoto, J., Amer. J. Vet. Res., 14, 307 (1953).

- Nakamura, J., and Ishii, S., 20 th Meeting of Jap. Soc. Vet. Sci. (1947).

${ }^{5}$ Plowright, W., and Ferris, R. D., Nature, 179, 316 (1957). - Svedmyr, A., Enders, J. F., and Holloway, A., Proc. Soc. Exp. Biol.
Med., 79, 296 (1952).

\section{Cleavage in Cheyletus eruditus (Acarina)}

IN his work on the embryology of the thelytokously parthenogenetic mite, Cheyletus eruditus, Hafiz ${ }^{1}$ states : "The single nucleus of the ovum rises to the surface of the yolk and by dividing gives rise to a single layer of cells forming the blastoderm". He also states that just before oviposition 4-7 small nuclei may be found entering the cortical layer of cytoplasm and that blastoderm formation is completed $2 \mathrm{hr}$. after deposition. Thus he aseribes to this mite a form of superficial cleavage which is already proceeding at the time of oviposition, a view not confirmed by my observations.

I have found that in $C$. eruditus the egg at oviposition is undergoing first maturation division and that the first cleavage division is not completed until $2 \mathrm{hr}$. later. At the latter time, if the egg is submerged in water and viewed under $\times 50$ binocular vision, a distinct line of demarcation may be seen across the transverse equator of the egg. The cytoplasm, in two equally divided masses, is seen in the centre of each 'cell' surrounded by the almost equally divided yolk. First cleavage division is therefore total, though it has not been ascertained if the yolk is completely divided. It seems likely that this division is no more than a superficial cleavage furrow, for it disappears with the completion, some $30 \mathrm{~min}$. later, of the second mitotic division. With each successive division, the nuclei, surrounded by their 